\title{
Requirement and Role of C5a in Acute Lung Inflammatory Injury in Rats
}

\author{
Michael S. Mulligan, ${ }^{\star}$ Elisabeth Schmid, ${ }^{\star \ddagger}$ Beatrice Beck-Schimmer, ${ }^{\star \ddagger}$ Gerd O. Till, ${ }^{\star}$ Hans P. Friedl, ${ }^{\ddagger}$ Robert B. Brauer, ${ }^{\S}$ \\ Tony E. Hugli, "Masayuki Miyasaka," Roscoe L. Warner, ${ }^{*}$ Kent J. Johnson, ${ }^{\star}$ and Peter A. Ward ${ }^{\star}$ \\ *Department of Pathology, University of Michigan Medical School, Ann Arbor, Michigan 48109; ${ }^{\ddagger}$ Department of Surgery, University of \\ Zurich Medical School, University Hospital, CH-8091 Zurich, Switzerland; ${ }^{\S}$ Department of Surgery, Technische Universität München, \\ München 81664, Germany; "Division of Immunology, Scripps Research Institute, La Jolla, California 92037; and "Department of \\ Bioregulation, Biomedical Research Center, Osaka University Medical School, 2-2 Yamada-oka, Suita 565, Japan
}

\begin{abstract}
The complement activation product, C5a, may play a key role in the acute inflammatory response. Polyclonal antibody to rat C5a was used to define the requirements for C5a in neutrophil-dependent inflammatory lung injury after systemic activation of complement by cobra venom factor (CVF) or after intrapulmonary deposition of IgG immune complexes. In the CVF model, intravenous infusion (but not intratracheal instillation) of anti-C5a produced a dosedependent reduction in lung permeability and in lung content of myeloperoxidase. In C6-deficient rats, CVF infusion caused the same level of lung injury (measured by leak of ${ }^{125}$ I-albumin) as found in C6-sufficient rats. In the IgG immune complex model of lung injury, anti-C5a administered intratracheally (but not intravenously) reduced in a dosedependent manner both the increase in lung vascular permeability as well as the buildup of lung myeloperoxidase. Treatment with anti-C5a greatly suppressed upregulation of lung vascular intercellular adhesion molecule-1 (ICAM1). This was correlated with a substantial drop in levels of $\mathrm{TNF} \alpha$ in bronchoalveolar fluids. These data demonstrate the requirement for C5a in the two models of injury. In the IgG immune complex model, C5a is required for the full production of TNF $\alpha$ and the corresponding upregulation of lung vascular ICAM-1. (J. Clin. Invest. 1996. 98:503-512.) Key words: neutrophils $\cdot$ C5a $\cdot$ complement $\cdot$ cobra venom factor $\bullet$ immune complexes $\bullet$ lung injury
\end{abstract}

\section{Introduction}

The complement system is well known to be necessary for full development of inflammatory injury in a variety of organs (reviewed in references 1-3). It has been shown that purified human C5a given intratracheally into hamsters or rabbits can cause pulmonary accumulation of neutrophils (4-6). C5-defi-

\footnotetext{
Address correspondence to Peter A. Ward, Department of Pathology, The University of Michigan Medical School, M5240 Medical Science I, Box 0602, 1301 Catherine Road, Ann Arbor, MI 48109-0602. Phone: 313-763-6384; FAX: 313-763-4782; E-mail:pward@umich.edu

Received for publication 27 March 1996 and accepted in revised form 14 May 1996.
}

1. Abbreviations used in this paper: $\mathrm{BAL}$, bronchoalveolar lavage; $\mathrm{CH} 50$, hemolytic complement; CVF, cobra venom factor; MPO, myeloperoxidase; sCR1, soluble complement receptor-1.

J. Clin. Invest.

(C) The American Society for Clinical Investigation, Inc.

0021-9738/96/07/0503/10 \$2.00

Volume 98, Number 2, July 1996, 503-512 cient mice have reduced lung inflammatory injury after deposition of IgG immune complexes (7). In the cobra venom factor $(\mathrm{CVF})^{1}$ model of lung injury, the CVF preparation must be able to activate not only C3 but also C5 (8), accordingly, hereditary absence of $\mathrm{C} 5$ protects the subject from lung injury (9). In vivo infusion of zymosan-activated plasma causes neutropenia $(10,11)$, but little evidence of lung injury unless the activated plasma is repetitively infused (12). In experimental systems, interference with complement availability can be achieved either by complement blockade using recombinant soluble complement receptor-1 (sCR1) $(13,14)$ or by the use of complement depletion procedures involving serial intraperitoneal injections of CVF $(15,16)$. Blockade or depletion of complement (such that plasma levels of C3 are reduced by $>95 \%$ ) in models of lung injury after either systemic activation of complement (by intravenous infusion of CVF) or intrapulmonary deposition of IgG immune complexes greatly reduces neutrophil influx and correspondingly diminishes the development of lung injury $(16,17)$.

In most biological models, the precise role of the complement in the development of inflammatory injury has not been defined. The anaphylatoxins, $\mathrm{C} 3 \mathrm{a}$ and $\mathrm{C} 5 \mathrm{a}$, may play a role in mast cell activation, resulting in release of histamine and other products (18). The anaphylatoxins can also bring about platelet activation (19) and may play a role in endotoxin-induced shock (20). C5a may be a major chemoattractant for and activator of phagocytic cells, but it can also directly activate endothelial cells to induce upregulation of P-selectin, thus facilitating adhesion of neutrophils (21). However, there has been little direct evidence demonstrating the in vivo requirement for $\mathrm{C} 5 \mathrm{a}$ in experimental inflammatory models or in clinical inflammatory states. In an earlier report, it is indicated that antibody-induced blockade of C5a reduces injury in endotoxininfused rats (20). C5b-9 can interact synergistically with TNF $\alpha$ to promote enhanced expression of endothelial E-selectin and intercellular adhesion molecule-1 (ICAM-1) (22), which in turn would likely enhance neutrophil recruitment. Aside from its cytotoxic effects, C5b-9 is also known to be able to activate macrophages to release proinflammatory cytokines ( TNF $\alpha$, IL-1) and oxidants (superoxide anion) $(23,24)$.

In the current studies, complement-dependent lung inflammatory injury was induced in rats either by intravenous infusion of CVF or by intrapulmonary deposition of IgG immune complexes. The IgG immune complex model may be useful for probing events that occur in human inflammatory injury associated with rheumatoid arthritis, systemic lupus erythematosus, immune complex-related glomerulonephritis (e.g., Berger's IgA nephropathy, IgG-related membranous nephritis, rapidly progressive crescentic glomerulonephritis, etc.), and a variety of vasculitis states where Ig and complement deposits have been well documented (reviewed in reference 25). The CVF model produces a picture that has several features similar to 
those found in adult respiratory distress syndrome (ARDS) of humans and also has some similarity to findings in humans undergoing intravascular activation of complement during cardiopulmonary bypass surgery (26) or during hemodialysis (27). These complement activation events appear to cause limited and reversible pathophysiological changes in lungs (28).

Based on the use of antibody to rat-C5a, we now demonstrate that the two experimental lung inflammatory reactions are C5a dependent. As a function of the experimental inflammatory model studied, these reactions differ with respect to the compartment (intravascular vs intraalveolar) in which C5a is playing a role. For unknown reasons, in the $\mathrm{IgG}$ immune complex model, C5a is required for full lung production of $\mathrm{TNF} \alpha$ and upregulation of lung vascular ICAM-1, both of which are known to play key roles in neutrophil recruitment in this model. These findings expand the role of C5a in lung inflammatory reactions.

\section{Methods}

Reagents. Except where specified, all reagents were purchased from Sigma Chemical Co. (St. Louis, MO). mAb 1A29 to rat ICAM-1 was of the $\mathrm{IgG}_{1}$ subclass. An isotype-matched mouse myeloma protein, MOPC-21, was also used. These antibodies were radiolabeled with ${ }^{125} \mathrm{I}$, using chloramine-T. Details of this methodology are described elsewhere (29).

Isolation and characterization of rat C5a. Rat serum was activated with zymosan particles (30) in the presence of a carboxypeptidase inhibitor. After acidification ( $\mathrm{pH} 4.5$ ), the supernatant fluid was lyophilized, redissolved in water and subjected to column chromatographic isolation involving gel filtration and ion exchange. In the final purification step, C5a was isolated with a mono-S column. SDSPAGE analysis revealed a single protein band.

Development of antibody to rat C5a. Rabbits were immunized with rat C5a (in complete Freund's adjuvant) obtained from zymosan-activated rat serum. After multiple boostings, serum was obtained and the $\mathrm{IgG}$ component fractionated as described below.

Purification of anti-C5a IgG. The IgG fraction of rabbit anti-rat serum was isolated by chromatography on a $1.5 \times 12 \mathrm{~cm}$ column of protein G Sepharose (Pharmacia Biotech AB, Uppsala, Sweden), equilibrated with binding buffer (DPBS, $\mathrm{pH}$ 7.5). The serum was mixed with 2 vol of binding buffer, applied to the column and incubated for $2 \mathrm{~h}$ by end-over-end rocking at $4^{\circ} \mathrm{C}$. The column was drained and washed with binding buffer until the absorbance in the eluates at $280 \mathrm{~nm}$ was below 0.02 . The $\mathrm{IgG}$-ligand interaction was dissociated by eluting six times with $1 \mathrm{ml}$ of $0.1 \mathrm{M}$ glycine ( $\mathrm{pH} 2.5$ ) with $200 \mu \mathrm{l} 1 \mathrm{M}$ Tris ( $\mathrm{pH}$ 8.8) present. The eluate was dialyzed four times in PBS ( $\mathrm{pH}$ 7.4) with decreasing concentrations of Tris/glycine, with no Tris/glycine in the last dialysis procedure. The IgG was then concentrated by centrifugation in Centricon 100 devices (Amicon Corp., Beverly, MA) with a molecular weight cutoff of $100 \mathrm{kD}$, to a final concentration of 2.5 to $5.5 \mathrm{mg} / \mathrm{ml}$.

Characterization of anti-rat C5a. Rat C5a purified from zymosan-activated rat serum containing a carboxypeptidase inhibitor was analyzed in SDS-PAGE and detected by staining with Coomassie blue. IgG enriched in anti-rat C5a (described below) was analyzed for its ability to block chemotactic responses of neutrophils to purified rat $\mathrm{C} 5 \mathrm{a}$ or to complement-activated serum. In addition, the antibody was added to whole rat serum to assess effects on hemolytic complement (CH50) activity (15). Finally, the antibody was used in Western blot analysis to define its ability to react with products in complement- or noncomplement-activated rat serum. With respect to gel electrophoresis/Western blot transfer techniques, along with reference molecular weight standards, samples were run in $15 \%$ SDSPAGE gels. Affinity (anti-C5a) purified products from normal and activated rat serum were loaded based on volume $(20 \mu \mathrm{l})$, whereas
$1 \mu \mathrm{g}$ purified rat C5a was used. In the latter case, the gel was then stained with Coomassie blue. For Western blots, proteins were transferred onto a polyvinylidene difluoride membrane (Schleicher \& Schuell, Inc., Keene, NH) using a semidry electrophoresis apparatus (LKB Multiphor II; Pharmacia Biotech AB) according to the manufacturer's instructions. The blot was reacted overnight with $5 \%$ milk and probed with anti-C5a antibody $(50 \mu \mathrm{g} / \mathrm{ml})$, followed by incubation with goat anti-rabbit horseradish peroxidase-conjugated antibody at a dilution of 1:1,000 (Bio-Rad Laboratories, Hercules, CA). Blots were further processed for enhanced chemiluminescence, again, according to manufacturers instructions (Amersham Corp., Arlington Heights, IL).

Neutrophil chemotaxis assay. Whole blood was obtained from healthy human volunteers and drawn into tubes containing citrate. Neutrophils were isolated by Ficoll and dextran (Pharmacia Biotech AB) separation. Remaining red blood cells were hypotonically lysed and the neutrophils washed and resuspended in DPBS-BSA. Neutrophils were fluorescein labeled with BCECF (Molecular Probes, Inc., Eugene, OR), washed again, and resuspended to a final concentration of $5 \times 10^{6}$ cells $/ \mathrm{ml}$ in HBSS-BSA. The wells of the bottom part of the chamber (NeuroProbe Inc, Cabin John, MD) were filled with $30 \mu \mathrm{l}$ of chemoattractant. The upper wells were filled with $44 \mu \mathrm{l}$ of the neutrophil suspension and the chambers were incubated for $30 \mathrm{~min}$ at $37^{\circ} \mathrm{C}$. The number of cells that migrated through the polycarbonate filter with a pore size of $3 \mu \mathrm{m}$ was measured in a cytofluorometer (Cytofluor 2300; Millipore Corp., Bedford, MA) (31). While rat neutrophils obtained from glycogen-induced peritoneal exudates responded chemotactically to purified $\mathrm{C5a}$, the background counts (in the absence of C5a) were high (data not shown); accordingly, the assays were confined to the use of purified human blood neutrophils that demonstrated very low background responses.

Bronchoalveolar lavage fluid content of TNF $\alpha$. Bronchoalveolar lavage (BAL) fluids were collected using repetitive lung lavage with 9.0 $\mathrm{ml}$ sterile saline. Approximately $80 \%$ of the instilled fluid was recovered from each animal. The fluids were centrifuged $(4,000 \mathrm{~g} \times 10$ $\min )$ to remove cells and the supernatant fluid stored at $-70^{\circ} \mathrm{C}$ before analysis. TNF $\alpha$ activity was determined by using equal volumes of $\log _{2}$ dilutions of samples in 96-well microtiter plates, which were coated with monolayers $\left(5 \times 10^{4}\right)$ of target LM cells (mouse fibroblast cell line derived from NCTC clone 929; American Type Culture Collections, Rockville, MD) in the presence of actinomycin D. A reference standard consisting of serially diluted recombinant murine $\mathrm{TNF} \alpha$ was used in additional sets of wells. The cells were incubated at $37^{\circ} \mathrm{C}$ for $18 \mathrm{~h}$ and the supernatants discarded. The remaining adherent cells were washed with sterile saline and stained with crystal violet. The plates were again washed with sterile saline, air dried, and read for absorbance at $620 \mathrm{~nm}$ in a microtiter ELISA reader (EL340; Bio-Tek Instruments, Inc., Winooski, VT). Units of TNF $\alpha$ were defined as the reciprocal of the dilution causing $50 \%$ cytolysis.

IgG immune complex alveolitis. Rabbit polyclonal $\mathrm{IgG}$ rich in antibody to BSA (anti-BSA) was purchased from Organon Teknika (West Chester, PA). Immune complex lung injury was induced by the intratracheal instillation of $2.5 \mathrm{mg}$ anti-BSA in $300 \mu \mathrm{l}$ sterile saline followed by the intravenous injection of $10 \mathrm{mg}$ BSA (in $1.0 \mathrm{ml}$ saline and containing $0.5 \mu \mathrm{Ci}^{125} \mathrm{I}$-BSA). Rats were killed $4 \mathrm{~h}$ after injection and the pulmonary circulation flushed with $10 \mathrm{ml}$ saline via pulmonary artery injection. Permeability indices, as a measure of lung injury, were determined by comparing the amount of ${ }^{125}$ I-labeled BSA present in lung parenchyma to the amount present in $1.0 \mathrm{ml}$ blood obtained at the time of death (16).

CVF-induced lung injury. CVF was isolated from cobra venom Naja naja by a combination of ion exchange and gel filtration techniques $(15,17)$. Unless otherwise noted, $4 \mathrm{U}$ CVF together with an aliquot of ${ }^{125} \mathrm{I}$-BSA $(0.5 \mu \mathrm{Ci})$ were injected intravenously in a single bolus into male 300 to $350 \mathrm{~g}$ Long Evans rats. Animals were killed 30 min later and the lung vasculature perfused with $10 \mathrm{ml}$ saline via pulmonary artery injection. Permeability indices were calculated according to methods described elsewhere (17). 
C6-deficient and C6-sufficient rats. To evaluate the possibility of complement components beyond C5 (e.g., the membrane attack complex, C5b-9) being involved in the development of CVF-induced acute lung injury, intravenous injections of $\mathrm{CVF}$ were performed in $\mathrm{PVG} / \mathrm{c}$ rats that were either $\mathrm{C} 6$ deficient $\left(\mathrm{PVG} / \mathrm{c}^{-}\right)$or $\mathrm{C} 6$ sufficient $\left(\mathrm{PVG} / \mathrm{c}^{+}\right)$. This complement-deficient strain of rats was discovered only recently and has been described in detail elsewhere $(32,33)$.

Intrapulmonary reconstitution of C5a in complement-depleted rats. Complement depletion in rats was accomplished by intraperitoneally injecting $25 \mathrm{U}$ CVF per animal at 36, 24, and $12 \mathrm{~h}$ before the induction of lung injury. This methodology reduces plasma $\mathrm{C} 3$ levels to less than $3 \%$ of their original levels (34). $2.5 \mu \mathrm{g}$ purified rat C5a mixed with the anti-BSA preparation were instilled intratracheally into complement-depleted and complement-intact rats in an effort to determine if C5a could restore the acute inflammatory response to IgG immune complex deposition in complement-depleted rats.

Lung measurement of myeloperoxidase (MPO). Lungs were homogenized (Polytron homogenizer; Tekmar Co., Cincinnati, $\mathrm{OH}$ ) $(4 \times 10 \mathrm{~s}$ at a setting of 4$)$ using $6 \mathrm{ml}$ of a polytron homogenizer buffer (50 mM phosphate, $\mathrm{pH} 6.0)$. Homogenates were then subjected to centrifugation $(3,000 \mathrm{~g} \times 30 \mathrm{~min})$ at $4^{\circ} \mathrm{C}$. MPO activity in supernatants was assayed by measuring the change (per min) in absorbance at $460 \mathrm{~nm}$ resulting from decomposition of $\mathrm{H}_{2} \mathrm{O}_{2}$ in the presence of $o$-dianisidine.

In vivo measurement of lung vascular ICAM-1. Animals undergoing IgG immune complex- or CVF-induced lung injury were intravenously injected $15 \mathrm{~min}$ before being killed with $1.0 \mu \mathrm{Ci}$ of ${ }^{125} \mathrm{I}$-labeled 1A29 anti-ICAM-1 mAb diluted with $200 \mu \mathrm{g}$ of unlabeled 1A29. Additional animals received similar amounts of labeled and unlabeled nonspecific MOPC-21. At the time of death (30 min after infusion of CVF), $1.0 \mathrm{ml}$ blood was obtained from the vena cava posterior and animals were then exsanguinated and the pulmonary circulation flushed with $10 \mathrm{ml}$ sterile saline. ${ }^{125} \mathrm{I}$ counts remaining in the lung and blood were assessed and the binding index determined as follows: binding index $=\mathrm{cpm}$ lung $/ \mathrm{cpm} 1.0 \mathrm{ml}$ blood. Details of this procedure are described elsewhere (29).

Statistical analysis. All data were subjected to one- and two-way analysis of variance. Individual group values were compared using the Newman-Keuls test, with a significant difference assigned when $P<0.05$. All data are presented as means \pm SEM.

\section{Results}

Characterization of anti-rat C5a antibody. $\mathrm{IgG}$ isolated from serum obtained from two rabbits immunized to rat C5a was tested for its ability to suppress chemotactic activity in whole rat serum after activation by glycogen $(10 \mathrm{mg}$ oyster glycogen type $\mathrm{II} / \mathrm{ml}$ rat serum, $37^{\circ} \mathrm{C}$ for $30 \mathrm{~min}$ ). Chemotactic responses to human neutrophils were measured using a cytofluorometric technique as described above. As shown in Fig. 1, activated rat serum induced an increase in cell migration as a function of the serum dilution $(A)$. A dose-dependent neutrophil chemotactic response was also observed with purified rat C5a $(B)$. A doseresponse suppression of chemotactic activity was determined after addition of increasing amounts of anti-C5a to either activated rat serum (1:20 dilution) or to the purified C5a preparation $(10 \mathrm{nM})$. On the basis of ELISA analysis, the concentration of C5a in glycogen-activated rat serum was $500 \mathrm{ng} / \mathrm{ml}$ (data not shown). Anti-C5a in doses of 6.25, 12.5, 25, 50, and $100 \mu \mathrm{g} / \mathrm{ml}$ activated rat serum resulted in 70, 91, 94, 87, and $74 \%$ reductions, respectively, in chemotactic activity for neutrophils, whereas suppression of chemotactic activity in purified rat C5a required higher doses of anti-C5a $(50-100 \mu \mathrm{g} / \mathrm{ml})$ $(C)$. The differences in the amounts of anti-C5a required for suppression of chemotactic activity in activated serum and in
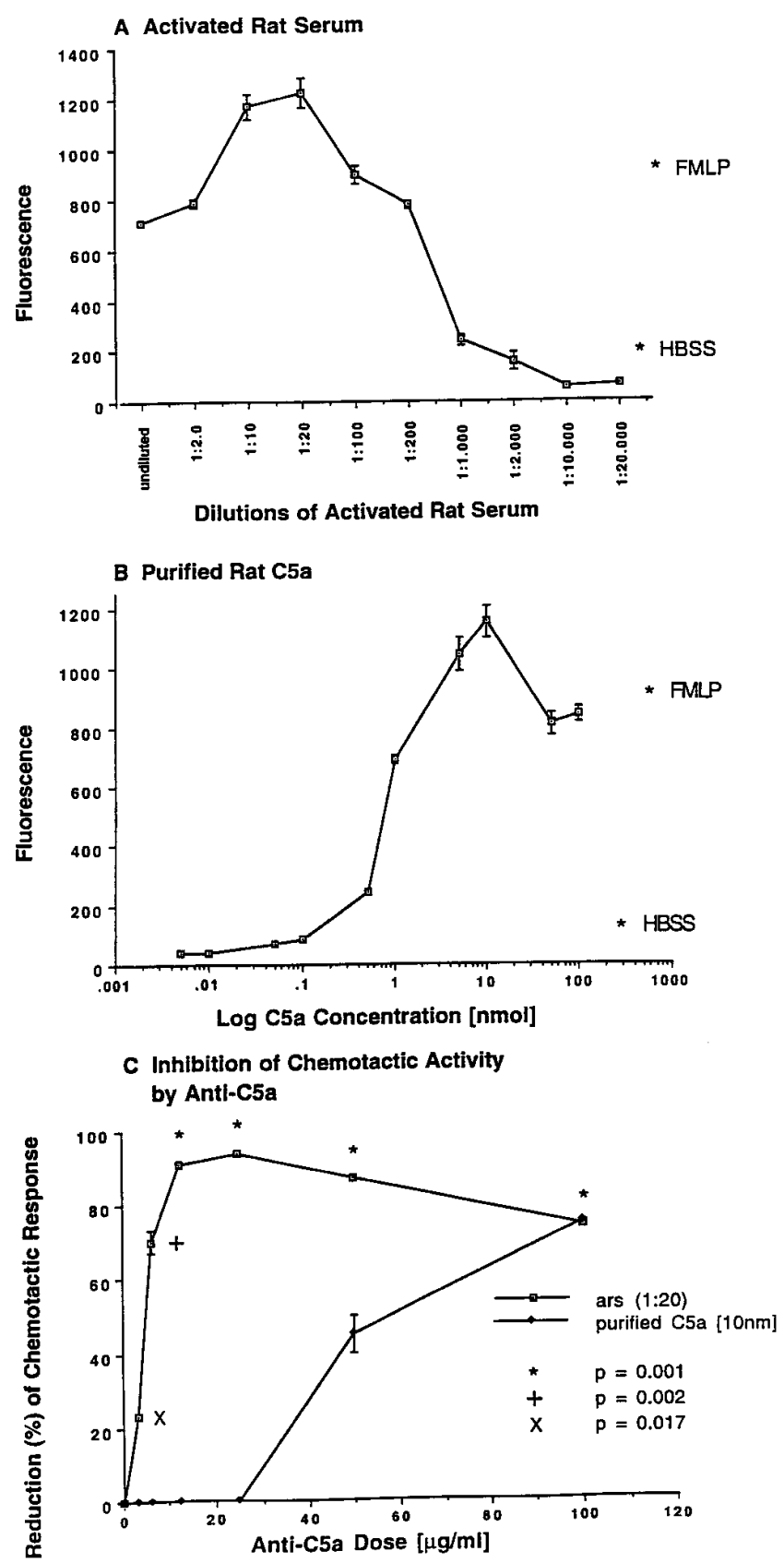

Figure 1. Levels of neutrophil chemotactic activity using dilutions of activated rat serum $(A)$, purified rat $\mathrm{C5}$ a $(B)$, and inhibition of chemotactic activity in these preparations by anti-rat C5a $(C)$. In $C$, the concentration of C5a was $10 \mathrm{nM}$. In many cases, error bars were so small as to be invisible. For each line graph, $n=4$.

the purified C5a preparation are probably due to the fact that considerably more (nearly sevenfold) purified C5a was used in the chemotaxis assay when compared to the amount of C5a des arg in the glycogen-activated serum (data not shown). When anti-C5a (at a final concentration of $50 \mu \mathrm{g} / \mathrm{ml}$ ) was added to $10 \mathrm{nM}$ formyl-Met-Leu-Phe, no reduction in the chemotactic response was found (data not shown).

Three types of analysis of C5a/C5a des arg were carried out. C5a purified from zymosan-activated rat serum in the presence of a carboxypeptidase inhibitor demonstrated a pro- 


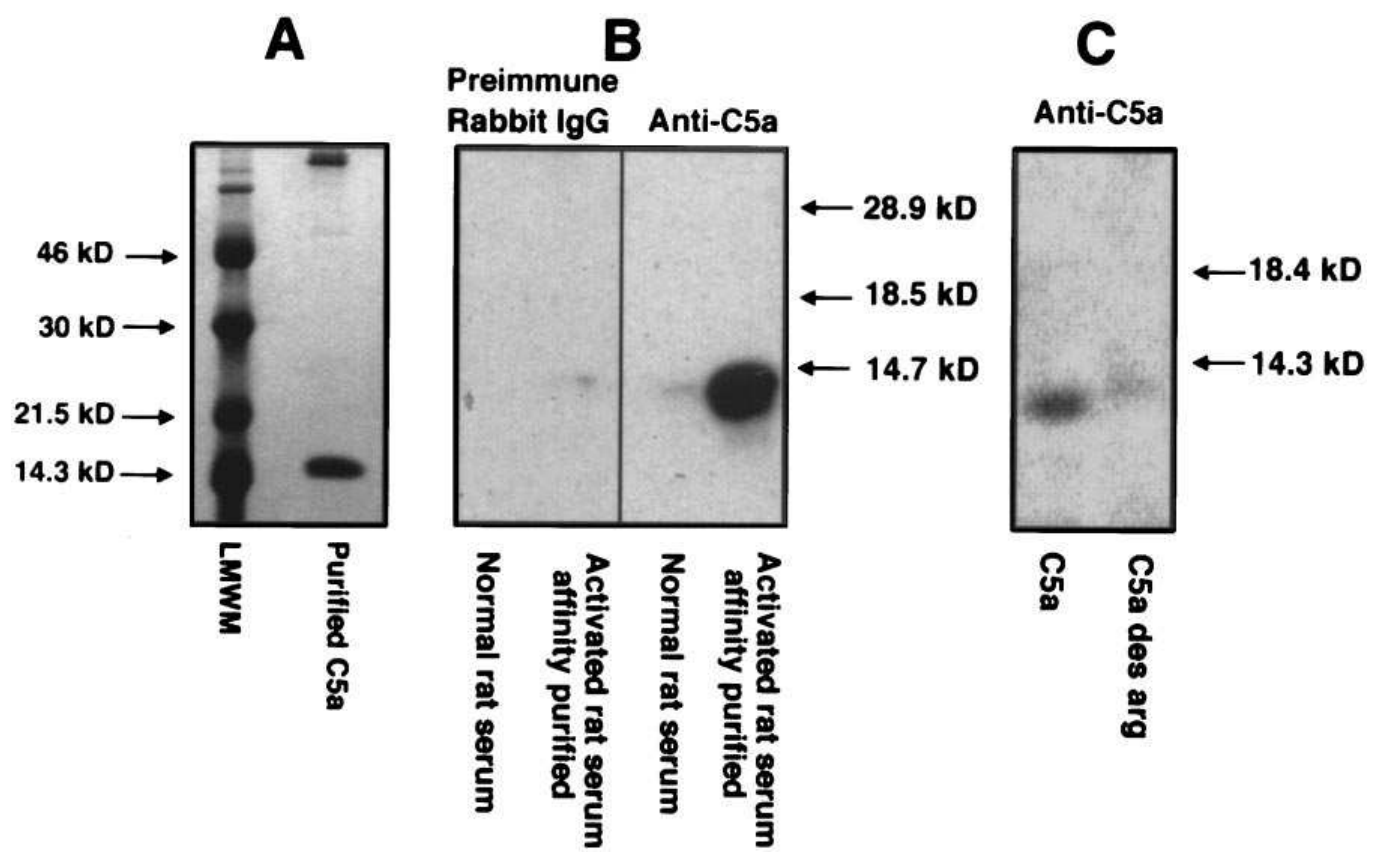

Figure 2. SDS-PAGE analysis of rat C5a. $(A)$ C5a purified from rat serum activated by zymosan in the presence of a carboxypeptidase inhibitor was detected by Coomassie blue staining. ( $L M M W$, low molecular weight markers.) (B) Immunoaffinity (anti-rat C5a) isolated fractions of normal rat serum or glycogen-activated rat serum (in the absence of a carboxypeptidase inhibitor) were obtained and subjected to Western blot analysis. For this, preimmune rabbit IgG or rabbit anti-C5a IgG were used. Reaction products in $B$ were detected by enhanced chemiluminescence techniques. (C) Rat C5a and rat C5a

des arg were electrophoretically separated in SDS-PAGE, and then transferred and subjected to Western blot analysis, and analyzed Western blot analysis, using enhanced chemiluminescence. Positions of molecular weight standards are shown.

tein band (as detected by Coomassie blue staining) in the region of the 14.3-kD marker (Fig. $2 A$ ). The material appearing near the origin represents nonconvalent tightly bound polymers of rat C5a, as determined by mass spectroscopy (T.E. Hugli, personal communication). Normal rat serum or rat serum that was activated by glycogen in the absence of a carboxypeptidase inhibitor was passed through an immuno-affinity column containing anti-rat C5a. Captured material was eluted with glycine buffer ( $\mathrm{pH} 2.5$ ), neutralized, and then subjected to SDS-PAGE and Western blotting, as described above. Reaction products were detected by enhanced chemiluminescence techniques. The results are shown in Fig. $2 \mathrm{~B}$, where little or no material was detected in either nonactivated or activated rat serum when preimmune rabbit IgG was used. In contrast, when anti-C5a IgG was used, a prominent product migrating just past the $14.7-\mathrm{kD}$ marker was found (Fig. 2 B). Little, if any, material was found in fractions from nonactivated serum. A third experiment was carried out in which purified rat $\mathrm{C5a}$ and C5a des arg purified from glycogen-activated serum by immunoaffinity methods were electrophoresed in SDS-PAGE and analyzed by Western blot analysis. The results, as shown in Fig. $2 C$, indicate the slightly slower position of C5a des arg, as would be expected when a positively charged amino acid (arginine) was lost from the C5a molecule (30).

Another analysis of the anti-C5a preparation involved addition of the antibody to normal rat serum, followed by analysis of total serum $\mathrm{CH} 50$ activity. The amounts of anti-C5a added were $0,10,20,40$, and $80 \mu \mathrm{g} / \mathrm{ml}$ rat serum, followed by incubation at $37^{\circ} \mathrm{C}$ for $30 \mathrm{~min}$. The serum samples were then analyzed for $\mathrm{CH} 50$ (serum dilution causing 50\% hemolysis) activity using sensitized sheep RBC and employing hemolysis as the endpoint (34). Under these conditions, the $\mathrm{CH} 50$ values (U/ml) were: 99, 94, 91, 93, and 94, respectively (data not shown). None of these values was statistically significantly different from the value obtained in rat serum to which no anti-
C5a was added, indicating that anti-C5a did not interfere with the hemolytic activity of rat $\mathrm{C} 5$. When rats were infused intravenously with $300 \mu \mathrm{g}$ anti-C5a and serum obtained $30 \mathrm{~min}$ later, there was no reduction in $\mathrm{CH} 50$ levels (data not shown) indicating that, like the in vitro data (described above), antiC5a did not adversely affect the function of intact C5.

Blockade by anti-C5a of CVF-induced acute lung injury. Immediately before intravenous infusion of $4 \mathrm{U} C V F$, rats received an intravenous injection of either $200 \mu \mathrm{g}$ preimmune rabbit IgG or 50-300 $\mu \mathrm{g}$ rabbit IgG anti-rat C5a. Animals were killed $30 \mathrm{~min}$ later, at which time lung permeability changes were determined (negative and positive values being

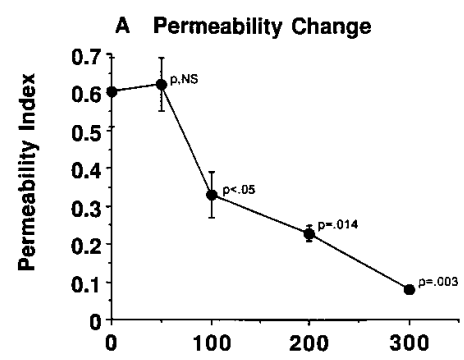

Figure 3. Protective effects of intravenous infusion of a range of doses of anti-rat C5a in CVF-induced acute lung injury, as defined by lung permeability changes $(A)$ and MPO content in lung $(B)$. For each data point, $n=4$. Statistical comparisons were made to the otherwise untreated positive control groups. The MPO value for normal lungs was $0.63 \pm 0.02$ Dose $(\mu \mathrm{g})$ Anti-C5a Administered Intravenously $(n=5)$. 
$0.05 \pm 0.001$ and $0.60 \pm 0.06$, respectively), together with analysis of lung MPO content (negative and positive control values being $0.27 \pm 0.04$, and $1.57 \pm 0.03$, respectively). The effects of treatment with anti-C5a are shown in Fig. $3 A$ and $B$. The intravenous administration of $50,100,200$, or $300 \mu \mathrm{g}$ rabbit $\mathrm{IgG}$ anti-rat C5a (as compared to intravenous infusion of $200 \mu \mathrm{g}$ preimmune rabbit IgG in reference positive controls) produced reductions in vascular permeability of $2 \%(P, \mathrm{NS}), 52 \%$ $(P=0.04), 69 \%(P=0.014)$, and $95 \%(P=0.003)$, respectively. Similarly, at the same concentrations of anti-rat C5a, lung MPO content was reduced 5\% $(P, \mathrm{NS}), 17 \%(P=0.008)$, $27 \%(P=0.002)$ and $39 \%(P<0.001)$, respectively. It is obvious from the data in Fig. 3 that anti-C5a is more effective in reducing the permeability increase than the MPO increase in CVF-infused rats. This may relate to the doses of C5a that are optimal for neutrophil activation $(10 \mathrm{nM})$ vs endothelial cell activation (100 nM) (21). Accordingly, it seems likely that anti-C5a-induced inhibition of endothelial cell expression would be favored over inhibition of neutrophil activation. Accordingly, partial neutrophil activation could occur, resulting in leukoaggregates entrapped in lung capillaries but, in the absence of P-selectin expression by endothelial cells, endothelial damage would be substantially attenuated. In the same series of experiments, when $200 \mu \mathrm{g}$ anti-rat C5a were administered intratracheally immediately before intravenous infusion of CVF, neither a reduction in permeability nor a fall in lung

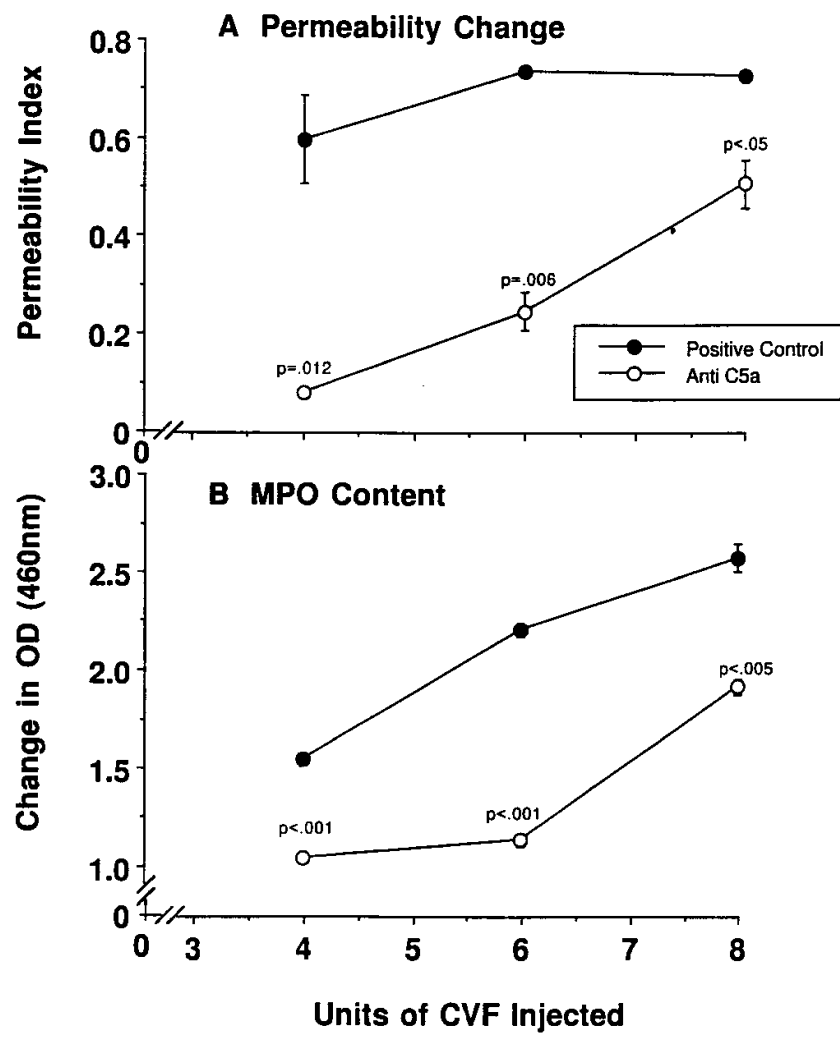

Figure 4. Protective effects of $300 \mu \mathrm{g}$ anti-rat C5a (infused intravenously) in CVF-induced lung injury as a function of dose of CVF (4, 6 , or $8 \mathrm{U})$. Parameters of injury were lung vascular permeability $(A)$ and lung MPO content $(B)$. The reference-positive controls received $300 \mu \mathrm{g}$ rabbit $\mathrm{IgG}$ purified from preimmune rabbit serum. For each data point, $n=4$. $P$ values were intergroup comparisons at equivalent doses of CVF.

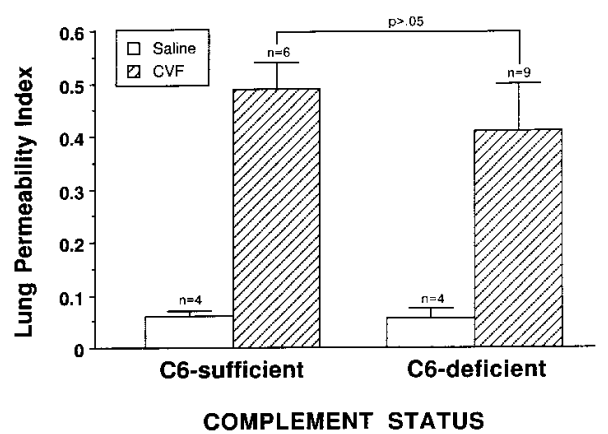

Figure 5. CVF-induced lung injury in C6-deficient and -sufficient rats. Animals were infused intravenously with sterile saline or $4 \mathrm{U}$ CVF, together with ${ }^{125}$ I-albumin. Albumin leak into lung (permeability index) was determined after killing of animals at $30 \mathrm{~min}$.

MPO content resulted (data not shown). These data indicate that CVF-induced lung injury requires the participation of C5a within the vascular compartment. The failure to achieve complete blockade with anti-C5a may be that it is not affinity purified, that neutrophils are releasing preformed cytokines and chemokines that contribute to neutrophil activation, or that other factors are also involved.

Protective effects of anti-C5a as a function of CVF dose. A series of studies was initiated to assess the protective effects of $300 \mu \mathrm{g}$ anti-C5a that was administered intravenously just before the intravenous infusion of 4,6 , or $8 \mathrm{U} \mathrm{CVF}$. The negative and positive controls received an intravenous infusion of $200 \mu \mathrm{g} \mathrm{IgG}$ purified from preimmune rabbit serum. The results are shown in (Fig. 4, $A$ and $B$ ). Positive controls receiving 4, 6, or $8 \mathrm{U}$ CVF showed permeability values of $0.60 \pm 0.09$, $0.74 \pm 0.01$, and $0.73 \pm 0.01$, respectively, while MPO values in the same group were $1.55 \pm 0.03,2.21 \pm 0.03$, and $2.58 \pm 0.07$, respectively (Fig. 4, $A$ and $B$ ). Under the experimental conditions employed, intravenous infusion of $0,2,4,6$, or $8 \mathrm{U} \mathrm{CVF}$ resulted in plasma levels ( $\mathrm{ng} / \mathrm{ml}$ ) C5a (at $5 \mathrm{~min}$ ): $4 \pm 1,531 \pm 83$, $835 \pm 51,1,548 \pm 236$, and 1,703 \pm 242 , respectively. Thus, C5a levels were proportional to the amounts of CVF infused (Schmid, E. and P.A. Ward, unpublished results). Treatment of rats with anti-rat C5a followed by infusion of 4,6 , or $8 \mathrm{U}$ CVF caused reductions in vascular permeability of $93 \%(P=$ $0.012), 71 \%(P=0.006)$, and $32 \%(P<0.05)$, respectively, while the corresponding reductions in MPO were 37\% $(P<$ $0.001), 55 \%(P<0.001)$, and $29 \%(P=0.005)$, respectively. Thus, the protective effects of anti-rat C5a were inversely related to the dose of CVF used.

Lack of requirement for C6 in CVF-induced lung injury. The availability of genetically C6-deficient rats as well as C6sufficient rats allowed us to determine if complement components beyond C5 (e.g., the membrane attack complex, C5b-9) might contribute to CVF-induced lung injury (as defined by extravascular leak of ${ }^{125} \mathrm{I}$-albumin). The results are shown in Fig. 5. Infusion of saline into C6-sufficient or C6-deficient rats caused low permeability values (permeability indexes of $<0.06)$. CVF infusion into C6-sufficient rats caused a nearly ninefold increase in the permeability index (to a value of $0.49 \pm 0.05$ ). In C6-deficient rats, the index rose eightfold (to $0.41 \pm 0.09$ ), but this value was not statistically different from that found in the C6-intact animals. Accordingly, it would appear that complement activation products beyond $\mathrm{C} 5$ do not 
participate in a significant manner in the development of lung injury in this model.

Reduction in IgG immune complex-induced lung injury after treatment with anti-rat C5a. Anti-rat C5a was added (in amounts of 50,100 , or $200 \mu \mathrm{g}$ ) to the anti-BSA preparation before intratracheal administration, followed by intravenous infusion of BSA $(10 \mathrm{mg})$. Lung injury was measured at $4 \mathrm{~h}$. The negative and positive reference controls received $200 \mu \mathrm{g}$ preimmune rabbit IgG that was mixed with the anti-BSA before its intratracheal instillation. The effects of anti-C5a on development of vascular permeability (leakage of ${ }^{125}$ I-albumin) and lung MPO content were assessed. In a companion set of animals, instead of intratracheal administration, $300 \mu \mathrm{g}$ antiC5a were infused intravenously. The permeability values (Fig. $6 \mathrm{~A}$ ) in the negative and positive control groups were $0.10 \pm 0.01$ and $0.68 \pm 0.01$, respectively, while the MPO values (Fig. $6 \mathrm{~B}$ ) in the same groups were $0.27 \pm 0.04$ and $1.80 \pm 0.07$, respectively. Intratracheal doses of 50, 100, or $200 \mu \mathrm{g}$ anti-C5a caused reductions in permeability values by $21 \%(P$, N.S. $)$, $55 \%(P=0.002)$, and 59\% $(P=0.001)$, respectively, whereas the intravenous infusion of $300 \mu \mathrm{g}$ anti-C5a reduced vascular permeability by only $24 \%(P$, NS) (Fig. $6 A$ ). In the same group of animals treated with 50,100, or $200 \mu \mathrm{g}$ anti-C5a intratracheally, MPO values fell by $21 \%(P, \mathrm{NS}), 52 \%(P=$ $0.002)$, and $57 \%(P=0.001)$, respectively. Intravenous infusion of $300 \mu \mathrm{g}$ anti-C5a failed to reduce lung content of MPO (Fig. $6 \mathrm{~B}$ ). It should be noted that, while not significantly protective in the $\mathrm{IgG}$ immune complex model of lung injury, 300 $\mu \mathrm{g}$ anti-C5a administered intravenously reduced lung vascular permeability by $95 \%$ in the CVF model of lung injury (Fig. 3). Thus, C5a is required in the airway compartment for recruitment of neutrophils and for full development of injury after intrapulmonary deposition of $\mathrm{IgG}$ immune complexes.

Reconstitutive effects of C5a in IgG immune complexinduced lung injury in complement-depleted rats. Rats were complement depleted by serial intraperitoneal injections of CVF, and then subjected to intrapulmonary deposition of $\mathrm{IgG}$ immune complexes and compared to complement-intact rats. Complement depletion is known to depress neutrophil accumulation and development of lung injury (16). Injury, as re-

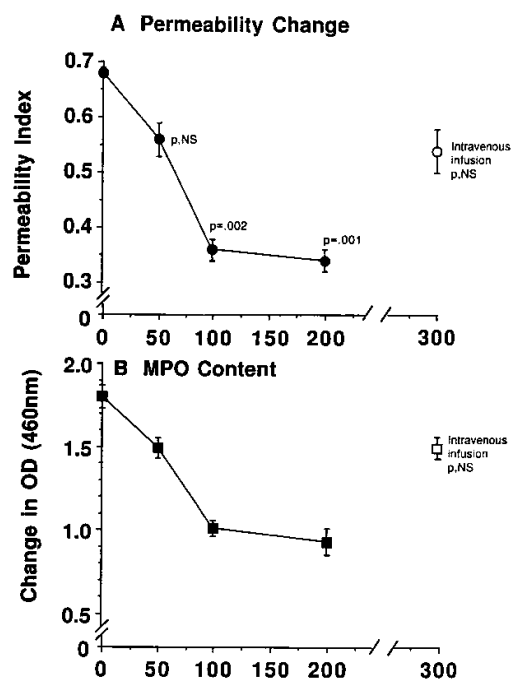

Dose $(\mu \mathrm{g})$ Anti-C5a Administered Intratracheally flected by increased vascular permeability, was measured together with lung content of MPO $4 \mathrm{~h}$ after intrapulmonary deposition of IgG immune complexes. In some cases, purified rat $\mathrm{C} 5 \mathrm{a}(2.5 \mu \mathrm{g})$ was added to the anti-BSA preparation before intratracheal instillation to assess effects of C5a on reactions in rats with intrapulmonary deposits of BSA/anti-BSA immune complexes. Complement-intact and -depleted animals were used. The permeability index (leakage of ${ }^{125} \mathrm{I}$-albumin) and lung MPO content were used as endpoints. The data are shown in Fig. 7. In this experiment, the negative and positive control permeability values were $0.12 \pm 0.01$ and $0.47 \pm 0.02$, respectively, while MPO values in the same groups were $0.27 \pm 0.02$ and $1.77 \pm 0.06$, respectively. When $2.5 \mu \mathrm{g}$ rat $\mathrm{C} 5 \mathrm{a}$ were added to PBS that was instilled intratracheally into lungs of the negative control group, the permeability index and MPO values rose modestly, more than doubling ( 0.22 and 0.55 , respectively). In the case of the positive controls in which both the mean permeability index and the mean MPO value were dramatically increased as compared to the negative controls (Fig. 7, $A$ and $B$ ), the addition of C5a to the anti-BSA prepa-

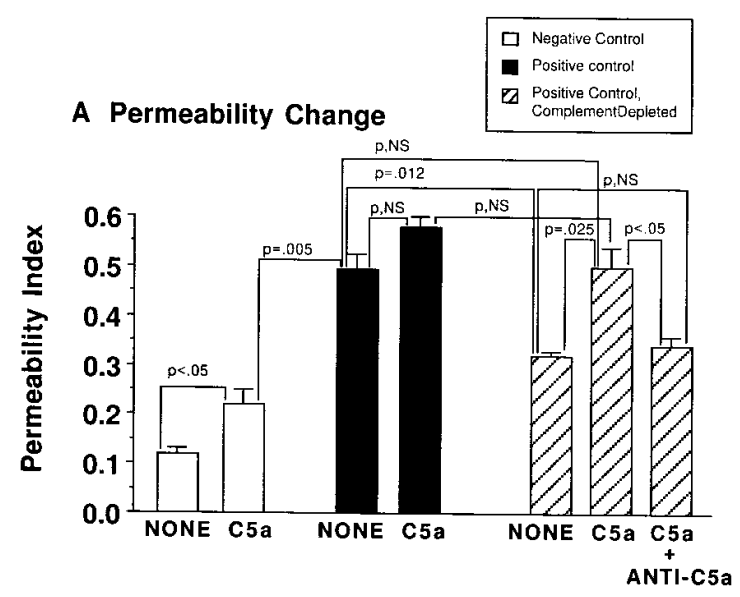

B MPO Content

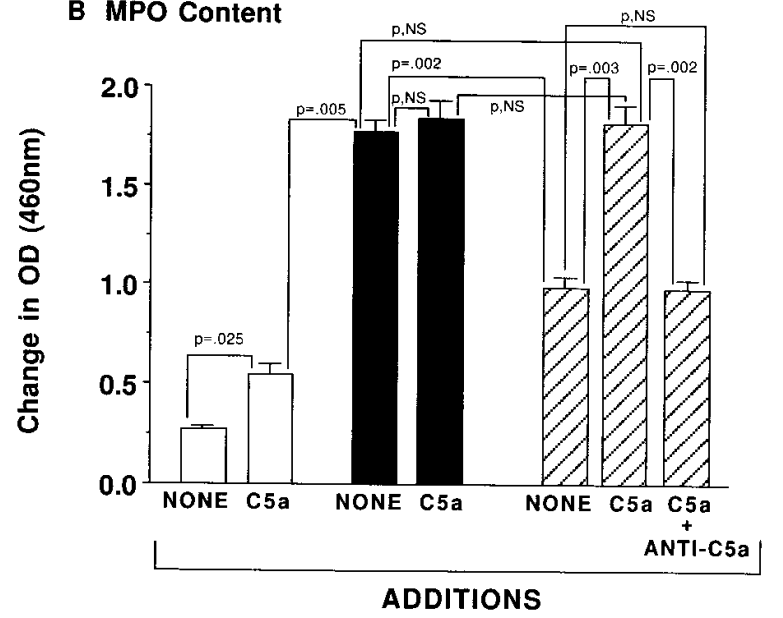

Figure 7. Reconstitution by C5a of injury in immune complex alveolitis. Lung injury after intrapulmonary deposition of $\mathrm{IgG}$ immune complexes in complement-intact and -depleted rats. Vascular permeability $(A)$ and lung MPO content $(B)$ were measured. In some animals, $2.5 \mu \mathrm{g}$ C5a were administered intratracheally (to saline-instilled lungs or lungs developing immune complex deposits) in the presence or absence of $200 \mu \mathrm{g}$ anti-rat C5a. For each column, $n=4$. 


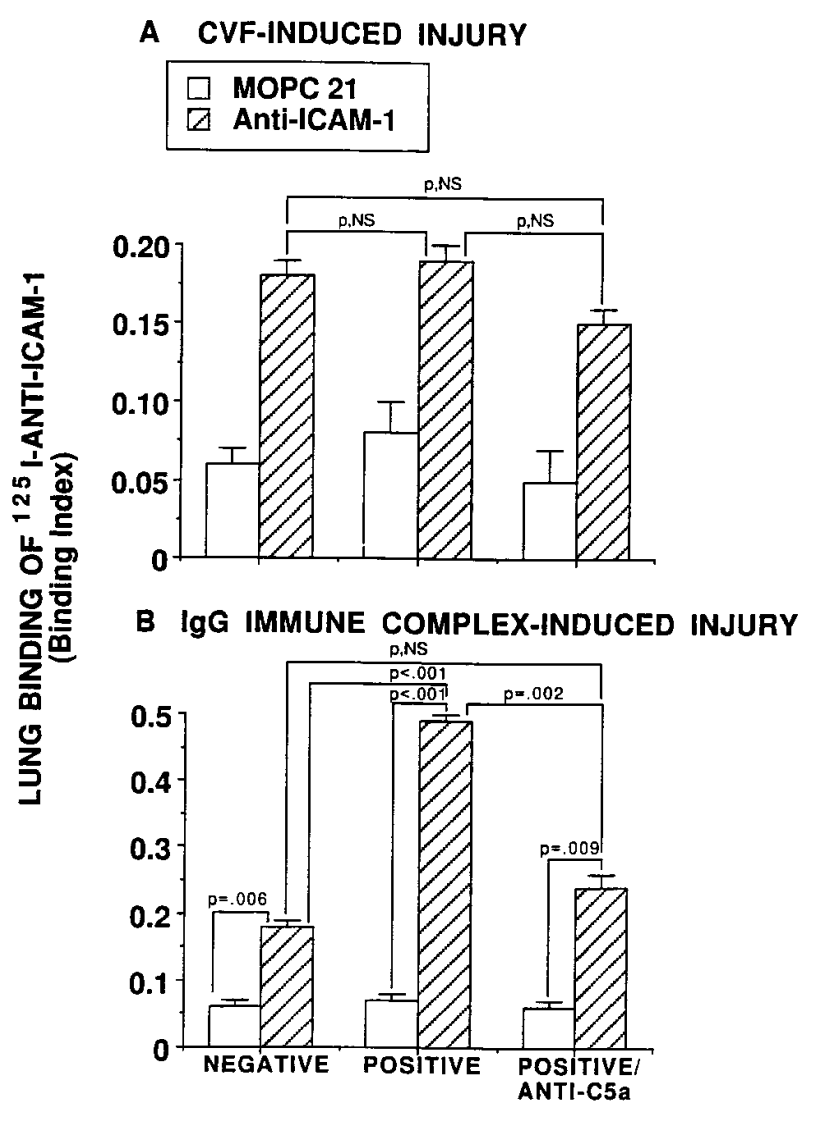

Figure 8. Relationship between C5a and lung vascular ICAM-1. Upregulation of lung vascular ICAM-1, as determined by lung fixation of ${ }^{125} \mathrm{I}-\mathrm{MOPC}-21 \mathrm{IgG}_{1}$ or ${ }^{125} \mathrm{I}$-anti-ICAM-1 $\mathrm{IgG}_{1}$ (1A29) in the CVF model of lung injury (at $30 \mathrm{~min})(A)$ or in the $\mathrm{IgG}$ immune complex model of lung injury (at $4 \mathrm{~h})(B)$. Positive control groups also received intravenously either $200 \mu \mathrm{g}$ preimmune rabbit IgG or $200 \mu \mathrm{g}$ anti-C5a intravenously $(A)$. Other animals received $200 \mu \mathrm{g}$ of either $\mathrm{IgG}$ preparation intratracheally together with anti-BSA $(B)$. Procedures for measuring binding of ${ }^{125} \mathrm{I}-\mathrm{MOPC}-21$ or ${ }^{125} \mathrm{I}$-anti-ICAM-1 are described in the text. For each vertical bar, $n=4$.

ration given to complement-intact rats did not further increase in a statistically significant manner either the permeability index or the MPO content in these positive control groups (Fig. 7 ). In the positive controls that had been complement depleted, the permeability index fell by $46 \%$ as compared to the complement-intact positive controls (Fig. $7 A$ ). The reason that complement depletion only reduces the permeability and MPO changes in the IgG immune complex model may be related to the fact that anti-C5a is most protective if given tracheally. This implies that complement activation is occurring mainly in the alveolar compartment. Access of CVF to the alveolar compartment for complement depletion procedures may be limited. In the presence of $2.5 \mu \mathrm{g}$ C5a, the permeability increase in the complement-depleted group was fully restored to levels found in the complement-intact positive controls. This restorative effect was nearly totally abolished in the copresence of $200 \mu \mathrm{g}$ anti-rat C5a (administered intratracheally) (Fig. $7 \mathrm{~A}$ ). In the case of lung MPO content, complement depletion caused a $54 \%$ fall in MPO content in positive controls; this reduction was fully restored in the presence of $2.5 \mu \mathrm{g} \mathrm{C} 5 \mathrm{a}$ (Fig. 7 B). The restorative effects of C5a were totally abolished in the copresence of anti-rat C5a (Fig. 7 B). Thus, under the experimental conditions used, C5a can fully restore the inhibitory effect of complement depletion in this model of lung injury. It appears that C5a plays a major role in lung inflammatory injury induced by deposition of $\mathrm{IgG}$ immune complexes and that exogenously administered C5a can fully restore inflammatory responses in complement-depleted animals.

Requirement for C5a in in vivo upregulation of lung vascular ICAM-1. Upregulation of lung vascular ICAM-1 was analyzed in rats after intravenous infusion of CVF or following intrapulmonary deposition of $\mathrm{IgG}$ immune complexes, and the requirement for $\mathrm{C} 5 \mathrm{a}$ in this upregulation was determined. In the CVF studies, the negative control group (receiving sterile saline intravenously) and the positive control group (receiving $4 \mathrm{U}$ CVF intravenously) also received an intravenous infusion of $200 \mu \mathrm{g}$ preimmune rabbit IgG or $200 \mu \mathrm{g}$ anti-rat C5a IgG. As shown by the data in Fig. $8 \mathrm{~A}$, fixation of ${ }^{125} \mathrm{I}-\mathrm{MOPC}-21$ to the lung vasculature was minimal and was not influenced by infusion of CVF in the presence of either preimmune or anti-C5a IgG. Fixation of ${ }^{125} \mathrm{I}$-anti-ICAM-1 to normal lung vasculature (negative controls) was nearly threefold more when compared to results with MOPC-21, even though the binding indices in both situations were quite small. As would be expected, no increase in lung vascular binding of anti-ICAM-1 occurred $30 \mathrm{~min}$ after intravenous infusion of CVF together with $200 \mu \mathrm{g}$ preimmune rabbit IgG. Similarly, the coinjection intravenously of $200 \mu \mathrm{g}$ anti-C5a together with CVF did not affect the low levels of lung vascular ICAM-1.

These results contrast with the findings in the $\mathrm{IgG}_{1}$ immune complex model of lung injury, which is known to be associated with $\mathrm{TNF} \alpha$-dependent upregulation of lung vascular ICAM-1 (29). For the current studies, negative and positive control groups received, together with the anti-BSA administered intratracheally, $200 \mu \mathrm{g}$ of either preimmune rabbit $\mathrm{IgG}$ or the same amount of anti-rat C5a IgG. In the negative control animals, binding of MOPC-21 to the lung vasculature was low while binding of anti-ICAM-1 was somewhat higher, reflective of constitutive ICAM-1 (Fig. $8 \mathrm{~B}$ ). In the positive control animals, which also received an intratracheal administration of $200 \mu \mathrm{g}$ preimmune rabbit IgG together with anti-BSA, binding of MOPC-21 remained very low, but the binding index for anti-ICAM-1 at $4 \mathrm{~h}$ rose nearly threefold in the positive control group (which also received $200 \mu \mathrm{g}$ preimmune IgG intratracheally). The binding index for anti-ICAM-1 in the positive control group was $\sim 10$-fold above the binding index for MOPC-21 (Fig. 8 B). In the presence of $200 \mu \mathrm{g}$ anti-rat C5a (instilled intratracheally), there was a dramatic reduction (by $81 \%, P=0.002)$ in the binding index related to lung vascular ICAM-1 expression (Fig. $8 \mathrm{~B}$ ). In fact, the binding index for anti-ICAM-1 was statistically not different from the value recorded in the negative controls. Thus, C5a is necessary for full upregulation of lung vascular ICAM-1 in animals undergoing intrapulmonary deposition of $\mathrm{IgG}$ immune complexes.

Effects of anti-rat C5a on TNF $\alpha$ levels in BAL fluids. Because it is known that in vivo upregulation of lung vascular ICAM-1 after intrapulmonary deposition of IgG immune complexes requires TNF $\alpha$ (29), BAL fluids were evaluated at $4 \mathrm{~h}$ in negative and positive control rats receiving intratracheal administration of $200 \mu \mathrm{g}$ anti-rat C5a or preimmune rabbit IgG, according to the details outlined in Fig. 9. In negative controls, BAL fluids contained very little TNF $\alpha(381 \pm 28.4 \mathrm{pg} / \mathrm{ml})$, while BAL fluids from positive controls (receiving preimmune 


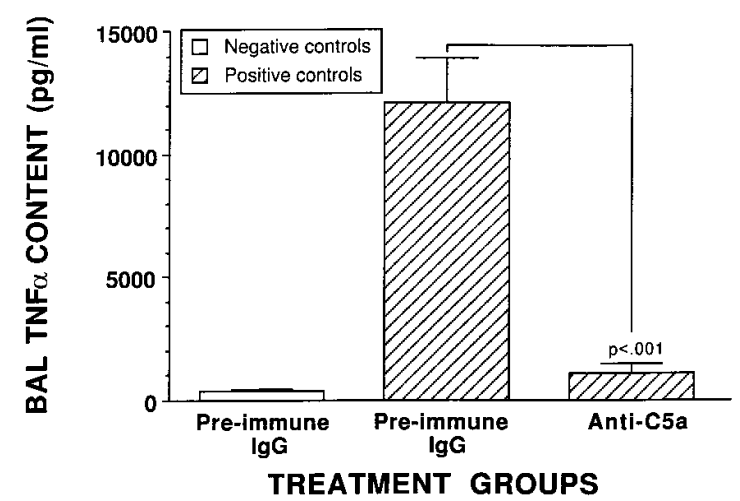

Figure 9. In vivo blocking of lung TNF $\alpha$ by anti-C5a. Effects of intratracheally administered anti-C5a $(200 \mu \mathrm{g})$ on BAL levels of TNF $\alpha$ $4 \mathrm{~h}$ after intrapulmonary deposition of IgG immune complexes. Reference positive controls received $200 \mu \mathrm{g}$ preimmune rabbit IgG intratracheally together with the anti-BSA. For each vertical bar, $n=4$.

IgG intratracheally) contained $12,042 \pm 1,671 \mathrm{pg} / \mathrm{ml}$, a 32 -fold increase over negative controls (Fig. 9). In striking contrast, BAL levels of TNF $\alpha$ in positive controls receiving anti-C5a intratracheally were dramatically reduced (by 91\%), to 1,061土 $383 \mathrm{pg} / \mathrm{ml}$ (Fig. 9). Accordingly, in this model of lung injury, $\mathrm{TNF} \alpha$ production requires C5a. Blockade of C5a dramatically reduced in vivo upregulation of lung vascular ICAM-1 (Fig. 8), probably because of its ability to cause profound reduction in BAL levels of TNF $\alpha$. The precise manner in which C5a facilitates lung generation of $\mathrm{TNF} \alpha$ is unknown.

\section{Discussion}

Although the requirements for complement in the CVF and IgG immune complex models of neutrophil-dependent lung injury have been well established, it has not been clear precisely which activation products of complement are involved in these inflammatory models of lung injury. While complement depletion or complement blockade results in protective effects that are accompanied by greatly reduced neutrophil accumulation, there are several mechanisms by which complement could be involved in these events, as described above. A variety of C5a-dependent mechanisms (chemotactic activity, induction of P-selectin, etc.) could be operative at the same time (35). C5a could also function as an activator of macrophages, resulting in production of cytokines and/or toxic oxygen products, the key role of TNF $\alpha$ and IL-1 being upregulation of lung vascular ICAM-1 (and E-selectin) after intrapulmonary deposition of IgG immune complexes (29). C5b-9 could also cause expression of endothelial P-selectin (Kilgore, K.S., B.F. Miller, J.S. Warren, personal communication) (36), or it could function together with TNF $\alpha$ or IL-1 to cause synergistic expression of endothelial E-selectin and ICAM-1 (22). Finally, C5b-9 could directly activate lung macrophages to produce cytokines and oxidants (23).

In the case of CVF-induced lung injury, any effects of complement activation products on cytokine production can be ruled out, since early response cytokines (TNF $\alpha$, IL-1) do not participate in this rapidly developing type of injury (37). On the basis of the data in the current report, in the CVF model of lung injury, which is P-selectin-dependent (38), the require- ment for C5a may be related to its ability to cause neutrophil as well as endothelial cell activation (see above). The fact that C5a blockade by anti-rat C5a greatly reduced neutrophil accumulation indicates a key role for C5a in this model of inflammatory injury. Neutrophils accumulate intravascularly in lung capillaries after intravenous infusion of CVF, and these cells appear to undergo activation by $\mathrm{C} 5 \mathrm{a}$, which results in homotypic cell aggregation and activation of NADPH oxidase. C5a is almost surely involved directly or indirectly in activating the vascular endothelial surface in a manner that leads to P-selectin-dependent neutrophil adhesion. The combined activation of neutrophils and endothelial cells appears to be required for the full production of lung vascular injury. In the IgG immune complex model of lung injury, cytokines play a key role in events leading to neutrophil accumulation and tissue injury $(29,39)$. In this model, C5a may be functioning as a chemoattractant of neutrophils as well as an activator of lung residential macrophages. The data in the current report demonstrate unequivocally that $\mathrm{C} 5 \mathrm{a}$ is required for the full development of lung injury in both models of neutrophil-dependent lung injury and that there is a compartmentalized role for C5a. In this model of injury, cytokines in addition to TNF $\alpha$ and IL-1 also participate in lung injury. MIP- $1 \alpha$, a C-C chemokine is expressed during the inflammatory reaction. It blockade protects against inflammatory injury in a manner that is associated with reduced TNF $\alpha$ levels (40). Accordingly, MIP-1a may function as an autocrine activator to facilitate TNF $\alpha$ production and, ultimately, upregulation of lung vascular ICAM-1. Currently the roles of two C-X-C chemokines, MIP-2 and cytokine-induced chemoattractant for neutrophils, are being explored (Shanley, T.P., H. Schmal, and P.A. Ward, submitted for publication).

In the cytokine-dependent model of lung injury triggered by intrapulmonary deposition of IgG immune complexes, anti-rat C5a was protective only if given intratracheally. This implies that, in this model, complement activation is occurring within the alveolar compartment. Whether there are sufficient amounts of the appropriate complement components within the alveolar compartment for generation of complement activation products or whether the components derive from the plasma proteins that leak into the alveolar compartment is not known at present.

The most interesting and unexpected aspect of this study was the finding that blockade of C5a in the IgG immune complex model of lung injury was associated with a substantial drop in the upregulation of lung vascular ICAM-1 (Fig. 8), an essential adhesion molecule required for neutrophil recruitment in this model (41). The reduced upregulation of ICAM-1 could be related to a dramatic drop in BAL levels of TNF $\alpha$, which have been previously shown to be required for upregulation of lung vascular ICAM-1 in this inflammatory model (29). The role of C5a in TNF $\alpha$ production may reflect the fact that C5a interacts synergistically with immune complexes to cause lung macrophages to generate maximal amounts of $\mathrm{TNF} \alpha$, but this remains to be proven. These results suggest that, in the immune complex model of inflammatory lung injury, C5a has functions that extend beyond a chemotactic pathway. In terms of chemotactic activities in BAL fluids of immune complex-injured rats, MIP-2, and cytokine-induced chemoattractant for neutrophils chemokines are the predominant chemotactic species while C5a is present as a minor contributor. (Schmid, E., and P.A. Ward, unpublished observations). 
The target of complement blockade has important theoretical and clinical implications. To date, aside from complement consumptive depletion, which is effective experimentally but not likely to be attractive in the clinical setting, there are three approaches that show experimental efficacy. sCR1 interferes with $\mathrm{C} 3$ and $\mathrm{C} 5$ convertases, reducing both $\mathrm{C} 3 \mathrm{a}$ and $\mathrm{C} 5 \mathrm{a}$ anaphylatoxin generation as well as formation of C3b and C5b-9 (13). As demonstrated in a variety of inflammatory models, sCR1 has effective antiinflammatory activity (14). The drawbacks of therapy with sCR1 may be product cost and interference in generation of protective opsonic products, such as $\mathrm{C} 3 \mathrm{~b}$. Recently reported is the use of antibody to C5, which blocks generation of C5 activation products (C5a and C5b-9) without interfering in generation of C3a (and presumably C3b) (42). When anti-human C5 was added to human blood that was perfused through a cardiopulmonary bypass machine, activation products of complement (C5a and C5b-9) were greatly diminished. This strategy for complement blockade is appealing, except for the fact that the antibody interferes with generation of C5b-9, which is important in lytic defenses against gram negative bacteria (2). Some bacteria contain C3 and C5 convertases that may generate biologically active cleavage products of $\mathrm{C} 3$ or C5 and, at higher doses, inactivate many of these peptides (43). It could be argued that, under such conditions, generation of C5a by bacterial enzymes might be protective by inducing local, acute inflammatory responses and, therefore, that blockade of C5a could theoretically impair protective inflammatory responses to bacteria. It has been reported that polyclonal antibody to human C5a des arg was protective in a model of sepsis (Escherichia coli) in nonhuman primates (44). However, the fact that animals infused with this antibody showed substantial reductions in blood levels of C5, as determined by immunoassay techniques (45), suggests that this antibody was reactive with intact $\mathrm{C} 5$, causing loss of serum $\mathrm{CH} 50$.

The current studies suggest that C5a may be an inviting target in clinical settings, whether through employment of a blocking antibody or use of nonantibody-based antagonists of C5a, such as peptides or reactive oligonucleotide preparations. To the extent that the studies in this report can be extrapolated to human diseases in which there is compelling evidence that complement activation has occurred (as described above), selective blockade of $\mathrm{C} 5 \mathrm{a}$ in the absence of interference with production of C5b-9 has many appealing aspects. That anti-rat C5a does not block the hemolytic activity of whole rat serum makes it unlikely that this antibody would interfere with formation of C5b-9. Additional understanding of the role of the complement system in the inflammatory response will provide important clues for development of complement-blocking approaches in human inflammatory disorders.

\section{Acknowledgments}

The authors thank Beverly Schumann for her assistance in the preparation of the manuscript.

This work is supported by National Institutes of Health grants GM-29507, GM-48477, HL-07517, and AI-31963.

\section{References}

1. Frank, M.M., and L.F. Fries. 1991. The role of complement in inflammation and phagocytosis. Immunol. Today. 12:322-326.

2. Spath, P.J. 1992. Role of complement in inflammation and bacterial killing. Curr. Stud. Hematol. Blood Transfus. 59:100-145.
3. Cooper, N.R., and G.R. Nemerow. 1985. Complement effector mechanisms in health and disease. J. Invest. Dermatol. 85(Suppl.):395-465.

4. Desai, U., D.L. Kreutzer, H.T. Showell, C.V. Arroyave, and P.A. Ward. 1979. Acute inflammatory pulmonary reactions induced by chemotactic factor. Am. J. Pathol. 96:71-83.

5. Henson, P.M., K.M. McCarthy, and G.L. Larsen. 1979. Complement fragments, pulmonary macrophages and alveolits. Am. J. Pathol. 97:93-105.

6. Larsen, G.L., K.M. McCarthy, R.V. Webster, T. Henson, and P.M. Henson. 1980. A differential effect of C5a and C5a des arg in the induction of pulmonary inflammation. Am. J. Pathol. 100:179-191.

7. Larsen, G.L., B.C. Mitchell, and P.M. Henson. 1981. The pulmonary response of C5 sufficient and deficient mice to immune complexes. Am. Rev. Respir. Dis. 123:434-439.

8. Till, G.O., M.L. Morganroth, R. Kunkel, and P.A. Ward. 1987. Activation of $\mathrm{C} 5$ by cobra venom factor is required in neutrophil-mediated lung injury in the rat. Am. J. Pathol. 129:44-53.

9. Tvedten, H.W., G.O. Till, and P.A. Ward. 1985. Mediators of lung injury in mice following systemic activation of complement. Am. J. Pathol. 119:92-100.

10. Hohn, D.C., A.J. Meyers, S.T. Gherini, A. Beckman, R.E. Morkison, and A.M. Chung. 1980. Production of acute pulmonary injury by leukocytes and activated complement. Surgery (St. Louis). 88:48-58.

11. Hosea, S., E. Brown, C. Hammer, and M. Frank. 1980. Role of complement activation in a model of adult respiratory distress syndrome. J. Clin. Invest. $66: 375-382$.

12. Perkowski, S.Z., A.M. Havill, J.T. Flynn, and M.H. Gee. 1983. Role of intrapulmonary release of eicosanoids and superoxide anion as mediators of pulmonary dysfunction and endothelial injury in sheep with intermittent complement activation. 1983. Circ. Res. 53:574-583.

13. Weisman, H.F., T. Bartow, M.K. Leppo, H.C. Marsh, Jr., G.R. Carson, M.F. Concino, M.P. Boyle, K.H. Roux, M.L. Weisfeldt, and D.T. Fearon. 1990. Soluble human complement receptor type 1: in vivo inhibitor of complement suppressing post-ischemic myocardial inflammation and necrosis. Science (Wash. DC). 249:146-151.

14. Mulligan, M.S., C.G. Yeh, A.R. Rudolph, and P.A. Ward. 1992. Protective effects of soluble CR1 in complement- and neutrophil-mediated tissue injury. J. Immunol. 148:1479-1485.

15. Cochrane, C.G., H.J. Muller-Eberhard, and B.S. Aikin. 1970. Depletion of plasma complement in vivo by a protein of cobra venom: its effect on various immunologic reactions. J. Immunol. 105:55-69.

16. Johnson, K.J., and P.A. Ward. 1974. Acute immunologic pulmonary alveolitis. J. Clin. Invest. 54:349-357.

17. Till, G.O., K.J. Johnson, R. Kunkel, and P.A. Ward. 1982. Intravascular activation of complement and acute lung injury. Dependency on neutrophils and toxic oxygen metabolites. J. Clin. Invest. 69:1126-1135.

18. Johnson, A.R., T.E. Hugli, and H.J. Muller-Eberhard. 1975. Release of histamine from rat mast cells by the complement peptides C3a and C5a. Immunology. 28:1067.

19. Meuer, S., U. Ecker, U. Hadding, and D. Bitter-Suermann. 1981. Platelet-serotonin release by $\mathrm{C} 3 \mathrm{a}$ and $\mathrm{C} 5 \mathrm{a}$ : two independent pathways of activation. J. Immunol. 126:1506-1509.

20. Smedegard, G., L. Cui, and T.E. Hugli. 1989. Endotoxin-induced shock in the rat. A role for C5a. Am. J. Pathol. 135:489-497.

21. Foreman, K.E., A.A. Vaporciyan, B.K. Bonish, M.L. Jones, K.J. Johnson, M.M. Glovsky, S.M. Eddy, and P.A. Ward. 1994. C5a-induced expression of P-selectin in endothelial cells. J. Clin. Invest. 94:1147-1155.

22. Kilgore, K.S., J. Shen, B.F. Miller, P.A. Ward, and J.S. Warren. 1995. Enhancement by the complement membrane attack complex of TNF-induced endothelial cell expression of E-selectin and ICAM-1. J. Immunol. 155:14341441.

23. Hänsch, G.M., M. Seitz, and M. Betz. 1987. Effect of the late complement component C5b-9 on human monocytes: release of prostanoids, oxygen radicals and of a factor inducing cell proliferation. Int. Arch. Allergy Appl. Immunol. 82:317-320.

24. Pertosa, G., E.A. Tarantino, L. Gesualdo, V. Montinaro, and F.P. Schena. 1993. C5b-9 generation and cytokine production in hemodialyzed patients. Kidney Int. Suppl. 41:221-225.

25. Cotran, R.S., V. Kumar, and S.L. Robins. 1994. The Kidney. In RobbinsThe Pathological Basis of Disease. 5th ed. W.B. Saunders Co., Philadelphia. 927-989.

26. Haslam, P.L., P.J. Townsend, and M.A. Branthwaite. 1980. Complement activation during cardiopulmonary bypass. Anaesthesia. 25:22-26.

27. Craddock, P.R., J. Fehr, A.P. Dalmasso, K.L. Brigham, and H.S. Jacob. 1977. Hemodialysis leukopenia: pulmonary vascular leukostasis resulting from complement activation by dialyzes cellophane membranes. J. Clin. Invest. 59: 879-888.

28. Jacob, H.S. 1980. Complement-induced vascular leukostatsis. Its role in tissue injury. Arch. Pathol. Lab. Med. 104:617-620.

29. Mulligan, M.S., A.A. Vaporciyan, M. Miyasaka, T. Tamatani, and P.A. Ward. 1993. Tumor necrosis factor $\alpha$ regulates in vivo intrapulmonary expression of ICAM-1. Am. J. Pathol. 142:1739-1749.

30. Cui, L., D.F. Carney, and T.E. Hugli. 1994. Primary structure and functional characterization of rat C5a: an anaphylatoxin with unusually high po- 
tency. Protein Sci. 3:1169-1117.

31. Jones, M.L., and P.A. Ward. 1992. Monocyte chemoattractant protein-1 in a rat model of pulmonary granulomatosis. Lab. Invest. 66:498-503.

32. Leenarts, P.L., R.K. Stad, B.M. Hall, B.J. Van Damme, Y. Vanrenterghem, and M.R. Daha. 1994. Hereditary C6 deficiency in a strain of PVG/ c rats. Clin. Exp. Immunol. 97:478-482.

33. Brauer, R.B., W.M. Baldwin, M.R. Daha, S.K. Pruitt, and F. Sanfilippo. 1993. Use of C6-deficient rats to evaluate the mechanism of hyperacute rejection of discordant cardiac xenografts. J. Immunol. 151:7240-7248.

34. Hill, J.H., and P.A. Ward. 1971. The phlogistic role of C3 leukotactic fragments in myocardial infarcts of rats. J. Exp. Med. 133:885-900.

35. McEver, R.P., J.H. Beckstead, K.L. Moore, L. Marshall-Carlson, and D.F. Bainton. 1989. GMP-140, a platelet $\alpha$-granule membrane protein, is also synthesized by vascular endothelial cells and is localized in Weibel-Palade bodies. J.Clin. Invest. 84:92-99.

36. Hattori, R., K.K. Hamilton, R.P. McEver, and P.J. Sims. 1989. Complement proteins C5b-C9 induce secretion of high molecular weight multimers of endothelial von Willebrand factor and translocation of granule membrane protein GMP-140 to the cell surface. J. Biol. Chem. 264:9053-9060.

37. Mulligan, M.S., C.W. Smith, D.C. Anderson, R.F. Todd III, M. Miyasaka, T. Tamatani, T.B. Issekutz, and P.A. Ward. 1993. Role of leukocyte adhesion molecules in complement-induced lung injury. J Immunol. 150:24012406.

38. Mulligan, M.S., M.J. Polley, R.J. Bayer, M.F. Nunn, J.C. Paulson, and P.A. Ward. 1992. Neutrophil-dependent acute lung injury: requirement for
P-selectin (GMP-140). J. Clin. Invest. 90:1600-1607.

39. Ward, P.A., and M.S. Mulligan. 1995. Role of adherence molecules in lung inflammation. In Physiology and Pathophysiology of Leukocyte Adhesion. D.N. Granger and G.W. Schmid-Schonbein, editors. Oxford University Press, New York. 313-322.

40. Shanley, T.P., H. Schmal, H.P. Friedl, M.L. Jones, and P.A. Ward. 1995 Role of macrophage inflammatory protein-1 $\alpha$ (MIP-1 $\alpha)$ in acute lung injury in rats. J. Immunol. 154:4793-4802.

41. Mulligan, M.S., G.P. Wilson, R.F. Todd, C.W. Smith, D.C. Anderson, J. Varani, T. Issekutz, M. Miyasaka, T. Tamatani, J.R. Rusche, et al. 1993. Role of $\beta 1, \beta 2$ integrins and ICAM-1 in lung injury following deposition of IgG and IgA immune complexes. J. Immunol. 150:2407-2417.

42. Rinder, C.S., H.M. Rinder, B.R. Smith, J.C.K. Fitch, M.J. Smith, J.B. Tracey, L.A. Matis, S.P. Squinto, and S.A. Rollins. 1995. Blockade of C5a and C5b-9 generation inhibits leukocyte and platelet activation during extracorporeal circulation. J. Clin. Invest. 96:1564-1572.

43. Ward, P.A., J. Chapitis, M.C. Conroy, and I.H. Lepow. 1973. Generation by bacterial proteinases of leukotactic factors from human serum and $\mathrm{C} 3$ and C5. J. Immunol. 110:1003-1009.

44. Stevens, J.H., P. O'Hanley, J.M. Shapiro, F.G. Mihm, P.S. Satoh, J.A. Collins, and T.A. Raffin. 1986. Effects of anti-C5a antibodies on the adult respiratory distress syndrome in septic primates. J. Clin. Invest. 77:1812-1816.

45. Hangen, D.H., J.H. Stevens, P.S. Satoh, E.W. Hall, P.T. O'Hanley, and T.A. Raffin. 1989. Complement levels in septic primates treated with anti-C5a antibodies. J. Surg. Res. 46:195-199. 